\title{
Modelling of a Laser yacht mast
}
A. S. Blicblau ${ }^{1}$
M. Singh ${ }^{2}$
A. Thwaites ${ }^{3}$
N. Welsh ${ }^{4}$

(Received 8 May 2010; revised 9 July 2010)

\begin{abstract}
The purpose of this work to investigate the deflection of a Laser yacht mast caused by trimming forces (in plane deflection) occurring within the Laser yacht rig and create a model that reflects this. Finite element analysis software is used for the creation and analysis of the model based on structural mechanics principles. Verification of the model is carried out through comparison with experimental results, where deflection is determined in different wind conditions, and improvements of the model are based on the disparity of the model and the experimental results.
\end{abstract}

\section{Contents}

\section{Introduction}

C462

2 The Laser design

C463

http://anziamj. austms.org.au/ojs/index.php/ANZIAMJ/article/view/2291 gives this article, (c) Austral. Mathematical Soc. 2010. Published July 23, 2010. ISSN 1446-8735. (Print two pages per sheet of paper.) 


\section{Experimental setup}

4 Numerical simulation

C467

5 The FEA models

C471

6 Correlation of FEA analysis with experimental results

7 Conclusion

$\mathrm{C} 478$

References

C479

\section{Introduction}

Yachts have been one of the oldest forms of transportation used by many civilisations, used for both recreational and competitive sailing. Sophisticated yachts such as those used in the Americas cup races undergo water tank testing correlated with finite element $(\mathrm{FE})$ and computational fluid dynamics (CFD) simulations to determine the optimum design for sails and keels for conditions for racing. Simulation and modelling of mast behaviour has been limited to ocean going and racing yachts. It is apparent from a number of workers $[3,4,5,6,10]$ that modelling of the mast is performed in stages where forces produced from trimming are first applied to obtain results on the mast deflection, followed then by forces distributed from the sail on the mast, due to wind forces, to obtain final deflection on the mast.

A common light boat used in these activities is a Laser, which is a monohull dinghy with a standardised design for the hull, mast/boom and sail or loft [11], and has evolved as an Olympic and world class yacht [7]. Recently, at the 2009 Nautel Laser Worlds and Masters World Championships, Australia won gold and silver $[8,9]$. It is often the interaction of the yachtsman with the sail and mast as a single entity which affects the outcome of the Laser yacht race. In particular, the skill and expertise of the sailor greatly influences the 
speed and manoeuvrability of the yacht. The yachtsman applies a force to the boom, and hauls the sail in one action to maximise the manoeuvrability of the dinghy. The boom deflection under an applied load regulates the sail and controls the speed of the Laser.

Simple design dinghies, such as the Laser, often undergo in situ testing to determine optimum sailing conditions in different strength winds. The aim of this work is to generate a theoretical FEA model for a Laser mast and sail combination which accurately predicts the deflection of a Laser yacht mast under different sailing conditions of light and heavy wind. Verification of the model is carried out through comparison to experimental results of mast deflection at different trimming under four wind conditions and refinement of the model based on the results of these comparisons. The emphasis is placed on employing experimental statically applied forces under laboratory conditions and analysing their effect on the mast deflection under different loading conditions. The main aim of this work is to correlate the deflected shape of the mast when a simulated wind force is applied with a computer model based on finite element methods. The results will give a deflection of the mast due to sail trimming of the Lasers' lines under sailing conditions in both light and strong wind. The results of this work will enable the Laser yacht sail sailor to manoeuvre the mast in predicted weather conditions using information from experimental and computer models to achieve optimum sailing tactics.

\section{The Laser design}

The Laser dingy has a hull length of 4.23 meters (13 feet 10 inches) with waterline length of $3810 \mathrm{~mm}$ ( 12.5 feet), a total weight of $59 \mathrm{~kg}(130 \mathrm{lb})$ with a two part aluminium cantilevered mast [11]. The experimental model is based on these dimensions as shown in Figure 1. With the two spars of the mast assembled this gives the mast an overall length of $6169 \mathrm{~mm}$, with the bottom spar having an external and internal diameter of $65 \mathrm{~mm}$ and $57 \mathrm{~mm}$ 
respectively and the top spar with external and internal diameters of $50 \mathrm{~mm}$ and $46 \mathrm{~mm}$ respectively. The boom has a total length of $2670 \mathrm{~mm}$ with the same internal and external diameters as the top mast spar being $50 \mathrm{~mm}$ and $46 \mathrm{~mm}$ respectively. The Laser can be broken down into four different main components: lines, plates, sail and spars (the mast and boom). The mast is a two piece cantilever, joined near the middle where the sails luff can be pulled over it like a sock, and holds up the sail vertically. The boom is a structural component used to hold the sail clew in place so that the foot of the sail may be shaped. Control of the angle of attack (sailing direction) is achieved through the tensioning of the mainsheet.

\section{$3 \quad$ Experimental setup}

On the experimental rig setup shown in Figures 1 and 2, there are three trimming forces applied to the setup, being the outhaul, downhaul and vang $[5,11]$. These forces are applied through tensioned lines (ropes), which are tensioned by the user to meet the required sailing conditions. The only other force that is external to the mast and boom is the tension force created by the sail on mast as it is stretched into the required sailing shape. These external forces are applied to the setup at particular locations. The outhaul connects the sail to the end of the boom via the clew eyelet and when purchased (applying tension) it tightens the sail horizontally across the boom. The downhaul provides purchase to the sail by pulling the sail over the mast and in turn shapes the luff of the sail and creates a deflection of mast by its self due the large cure of the sail luff being pulled over the mast. The vang is a tension force that exists between the mast and boom which creates a force that counteracts the moment caused by the sail force and keeps the boom in static equilibrium.

With the test rig fully assembled, the sail is trimmed for light wind conditions followed by heavy wind conditions where the force occurring in lines are recorded. A light (0-3 knots) and heavy wind (17+ knots) set of conditions 


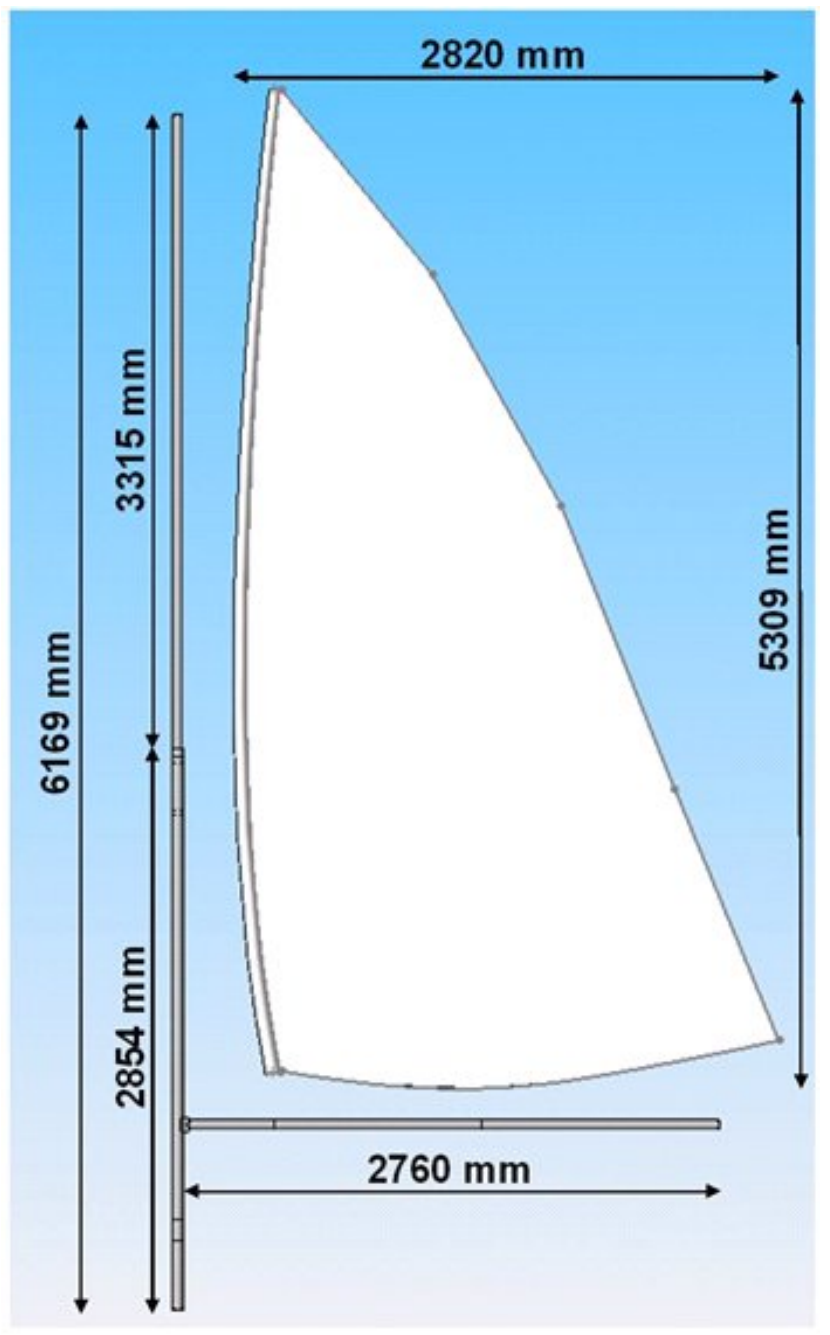

Figure 1: Dimension of the Laser Rig (Mast and Boom). 


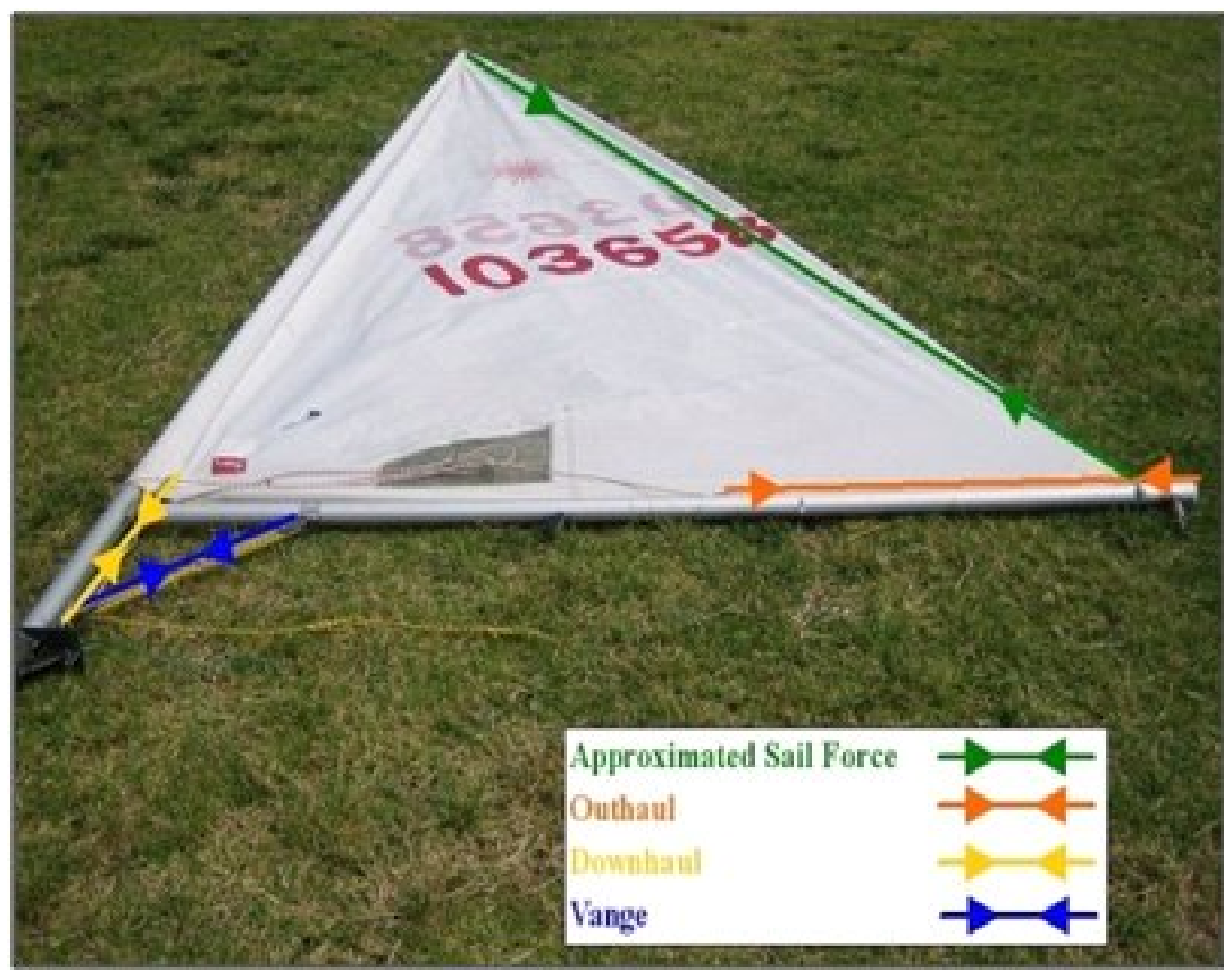

FiguRE 2: Experimental assembly of Laser rig (mast and boom) with the applied forces (outhaul, downhaul and vang). 
are set as the sailing limits. This is because little deflection occurs in a light wind where the sail is given a large curve/belly whereas in heavy winds the sail is flattened out. The set up for the light and heavy wind are only approximations of how the actual sail would be trimmed.

For most yachts, the pre-tensioning loads in the lines (outhaul, downhaul and vang) as shown in Figure 2, are often ignored as they are presumed to have little effect in the defection on the mast. However, a Laser does not have side stays to support it - the mast sits in a slot in the hull of the yacht - so that initial mast deflection occurs due the tensioning of the lines. In the experimental work the line inputs are controlled and resultant mast deflections are measured.

A housing fixture was made to imitate the mast hole in the hull of the laser that holds the mast in place. This enables all the input lines to be tensioned similar to a real life situation and allows the mast to bend as it would when riding the yacht. A physical grid needs to be setup adjacent to the laser model to ensure that the mast is aligned the same each time the test is run and to create a reference point to measure the deflections. With the test rig fully assembled, the sail is trimmed for what would be a good general set up for light wind conditions followed by heavy wind conditions where the force occurring in lines are recorded from the spring balances. The forces for medium and strong wind conditions are found by interpolating between the low and heavy wind condition for values of one third and two thirds of the forces, respectively.

\section{$4 \quad$ Numerical simulation}

Consider a beam subjected to pure bending. The deformation of a beam section is shown in Figure 3. During bending EF stretches to become $E^{\prime} F^{\prime}$, but $\mathrm{GH}$, being at the neutral axis, is unstrained when it becomes $\mathrm{G}^{\prime} \mathrm{H}^{\prime}$. Therefore, if $R$ is the radius of curvature of $\mathrm{G}^{\prime} \mathrm{H}^{\prime}$, then the longitudinal strain 


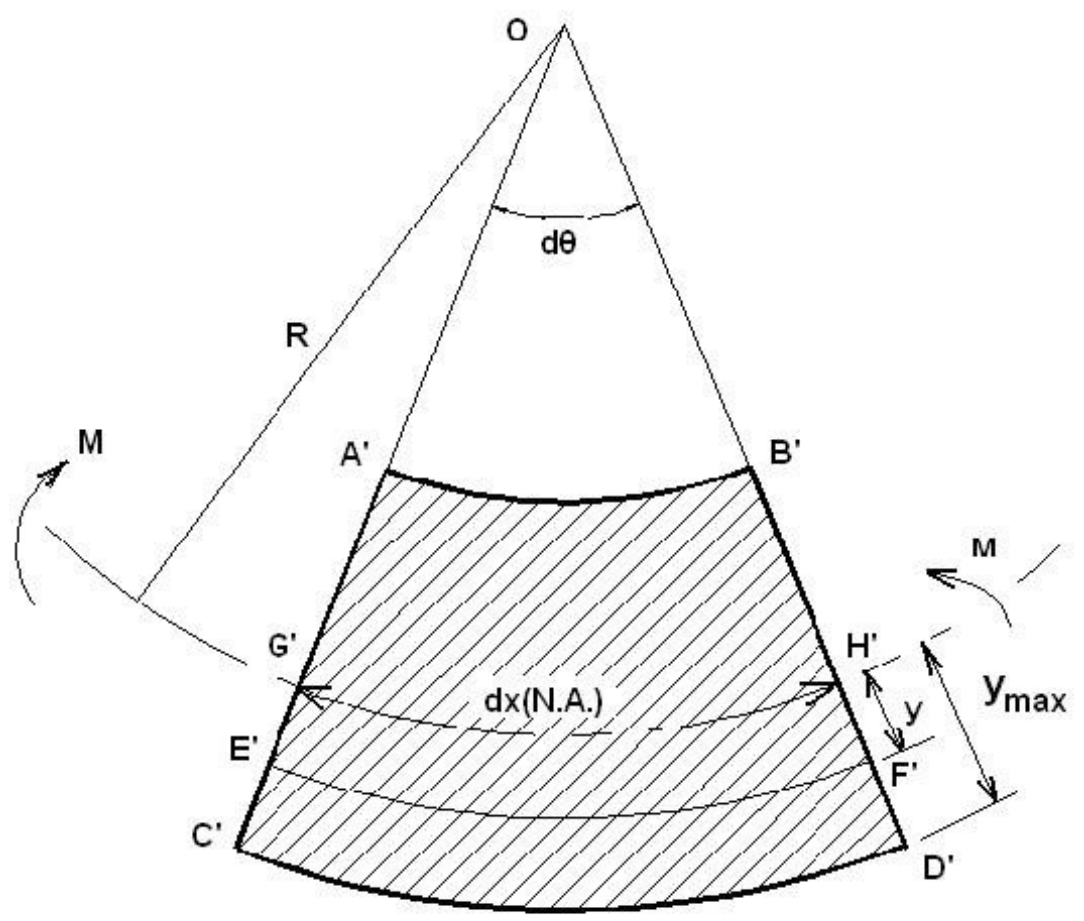

Figure 3: Deformations in pure bending of a beam [2].

in fibre $E^{\prime} F^{\prime}$ is $\varepsilon_{x}=\left(E^{\prime} F^{\prime}-E F\right) / E F$ or

$$
\varepsilon_{x}=\frac{(R+y) \times d \theta-R \times d \theta}{R \times d \theta}=\frac{y}{R} .
$$

Using Young's Modulus relationship $\epsilon_{x}=\sigma_{x} / E$, equation (1) becomes

$$
\sigma_{x}=\frac{y \times E}{R} .
$$

From Figures 3 and 4 consider an element of area, $d A$, at a distance $y$ from some arbitrary location on the neutral surface. The moment of the element 


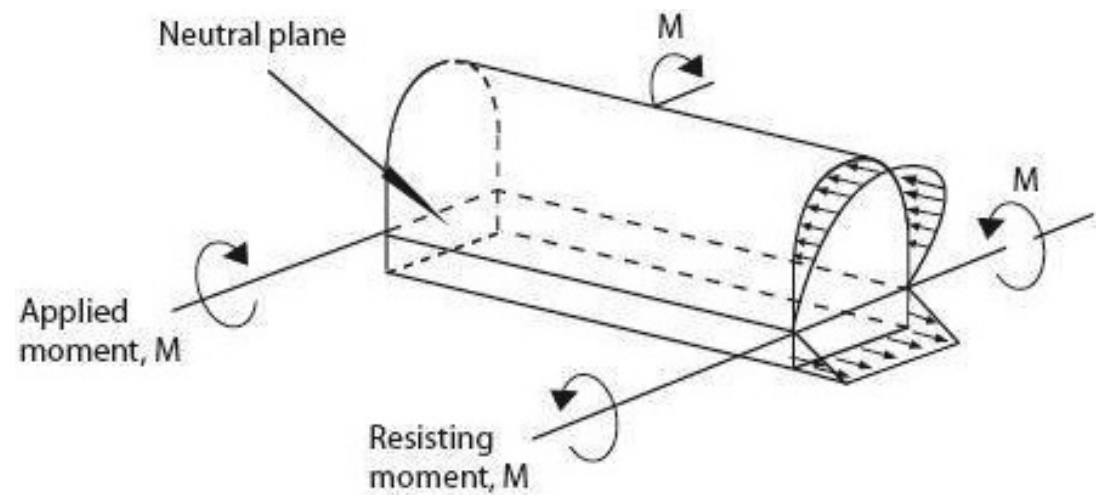

FiguRE 4: The internal resisting moment [2].

about the neutral surface is

$$
\mathrm{dF}_{x}=\sigma_{x} \times \mathrm{d} A
$$

Therefore the total internal resisting moment is

$$
M_{\text {internal }}=\int_{A} y \times \sigma_{x} \times d A,
$$

which yields

$$
M_{\text {internal }}=\frac{E}{R} \int_{A} y^{2} \times d A .
$$

Thus the second moment of area results in

$$
M_{\text {internal }}=\frac{E \times I_{x}}{R} .
$$

In Figure 5, $\theta$ is the angle which the tangent to the curve at $\mathrm{C}$ makes with the $x$ axis. The angle $(\theta-d \theta)$ is the angle which the tangent to the curve at point $\mathrm{D}$ makes with the $x$ axis. The normals to the curve at $\mathrm{C}$ and $\mathrm{D}$ meet at $O$. The point $O$ is the centre of curvature and $R$ is the radius of curvature to the small portion $\mathrm{CD}$ of the deflection curve of the neutral axis. 


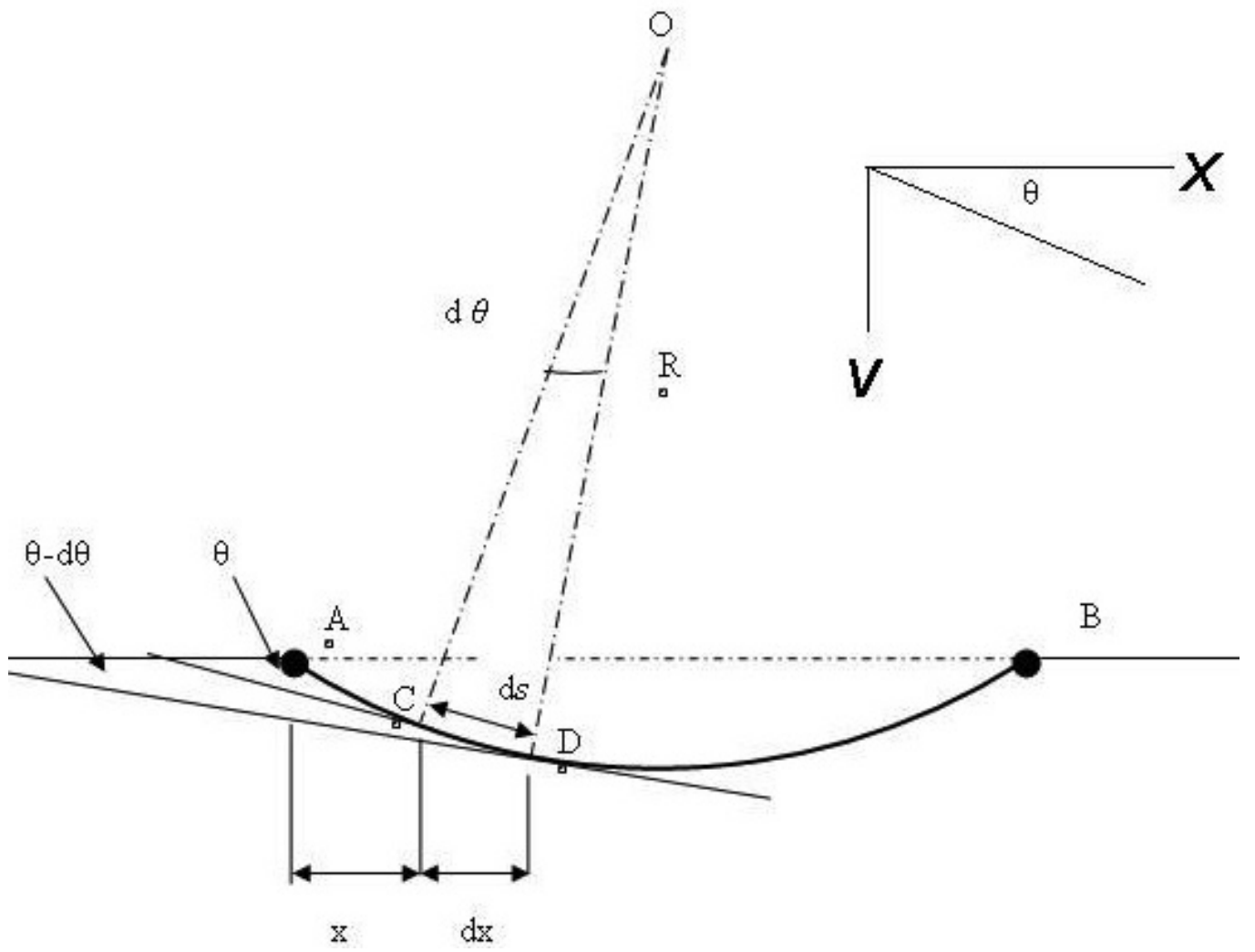

Figure 5: Deflections of the neutral axis [2]. 
Deflections of the neutral axis are denoted by the symbol $v$ as shown in Figure 5, measured positive downwards, and are assumed to be relatively small, giving a flat form of deflection curve. Therefore little error is introduced in assuming that $\mathrm{d} s \approx \mathrm{R} d \theta$, that $\theta \approx \tan (\theta)=\mathrm{d} v / \mathrm{d} x$, and hence that $\frac{\mathrm{d} \theta}{\mathrm{d} s}=\mathrm{d}^{2} v / \mathrm{d} x^{2}$. The internal resisting moment results in

$$
\frac{M_{\text {internal }}}{E \times I_{x}}=-\frac{d^{2} v}{d x^{2}}
$$

The first integration of Equation (7),

$$
\frac{\mathrm{d} v}{\mathrm{~d} x}=\frac{1}{\mathrm{EI}} \int-\mathrm{M}_{\text {internal }} \times \mathrm{d} x+\mathrm{C},
$$

gives the slope of the beam at a distance $x$ along its length. The second integration of Equation (7),

$$
v=\frac{1}{E I} \int-M_{\text {internal }} \times d x+C x+C_{1},
$$

gives the deflection of the beam at a distance $x$ along its length.

\section{The FEA models}

Four models of the Laser are first designed in SolidWorks and the analysis carried out with COSMOSWORKS using the FEA program affiliated with SolidWorks [1]. These models are developed iteratively ranging from: a one piece mast, a one piece mast and boom, an assembled mast, and a fully assembled mast and boom (which is indicative of the experimental setup). The force applied to all four models is taken from the experimental analysis for each of the two extreme wind conditions of light wind and heavy wind. For all models the material used for the spars is aluminium alloy 6061-T4. 
The FEA one piece mast model is a combination of hollow top and bottom spars of the mast with $360 \mathrm{~mm}$ removed from the bottom. The model has mesh parameters from coarse $26.83 \mathrm{~mm} \times 1.342 \mathrm{~mm}$ to fine $6.707 \mathrm{~mm} \times 0.6707 \mathrm{~mm}$. The FEA one piece mast and boom model is a refinement of the FEA one piece mast model, with the introduction of the boom. The model is a combination of hollow top and bottom spars of the mast with a solid connection to the hollow mast.

The FEA assembly of mast model is a refinement of the FEA one piece mast and boom model, with the mast modelled as an assembly of the two separate spars which reflect the actual Laser mast. Although both spars have plastic and metal fittings, both spars have been modelled as a solid piece.

The FEA assembly of mast and boom model as shown in Figure 6, with mesh geometry, is a refinement of the FEA assembly of mast model, with the mast (assembly of two spars) and boom (connected via pin joint) modelled as an assembly which reflects the actual Laser rig including interactions. The model has mesh parameters from coarse $32.09 \mathrm{~mm} \times 1.605 \mathrm{~mm}$ to fine $8.023 \mathrm{~mm} \times 0.4011 \mathrm{~mm}$. A mesh size of $16.05 \mathrm{~mm} \times 0.8023 \mathrm{~mm}$ is used. As there is contact between the spars, a global contact parameter of 'bonded' is selected for the interactions, which has the effect of joining the two poles together as one part. The global contact also makes sure the joint between the mast and the boom fix to one another.

The force applied to all models is taken from the experimental analysis for each of the wind condition of light wind and heavy wind. For both models the material used for the spars is aluminium alloy 6061-T4. 


\section{Correlation of FEA analysis with experimental results}

In order to validate the FEA models experimental testing is conducted to examine mast deflections. Figures 7 and 8 compare the deflection of all the FEA models with the experimental results under two extreme different wind conditions. Figure 7 shows that there is minimal difference in deflection between the experimental rig, and the all the FEA models' deflections. Hence, the FEA one piece mast model deflections (approximately less than $20 \mathrm{~mm}$ ) indicate that the assumptions made for the theoretical model are correct. Further, the minimal difference in deflection validates the use of FEA as a tool for predicting deflection in a Laser yacht mast under light wind conditions.

While the FEA one piece mast model validated the theoretical model, the FEA model used is very basic and a more realistic approximation can be achieved by including more detail to the model. The addition of the boom to the FEA assembly of mast model allows the interaction between the mast and boom to be taken into consideration simulating the interaction of the actual setup.

Figure 8 shows that there is a good correlation between heavy wind conditions and experimental results. These results are from an improvement of the FEA assembly of mast model, which can be selected for all wind conditions.

An illustration of the FEA model and experimental similarity under heavy wind conditions is shown in Figures 9 and 10. The deflection of the mast as shown in Figure 9 at the extremity for the FEA analysis is approximately $328 \mathrm{~mm}$ which compares well with a deflection, as shown in Figure 10, as $261 \mathrm{~mm}$. To consolidate the modelling, actual deflections under sailing conditions would be required.

However, even with the limited experimental equipment under laboratory stationary conditions, the FEA model is a good indicator of actual deflections under real sailing conditions. This data can be used as a guide for the yachtsman when manipulating the sail to achieve maximum wind thrust and 


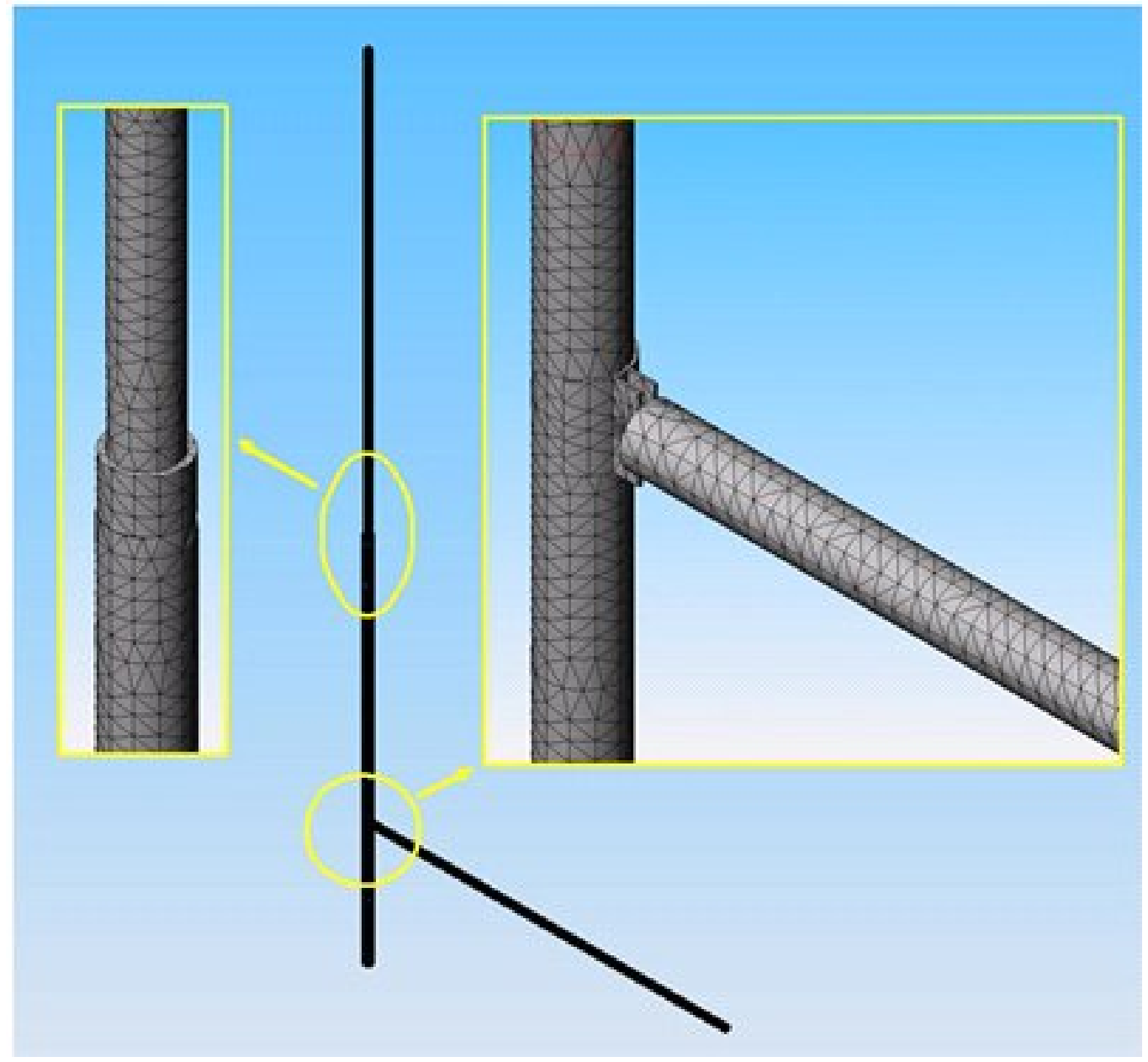

FigURE 6: View of mesh size used in FEA assembly of mast and boom model. 


\section{Light wind conditions}

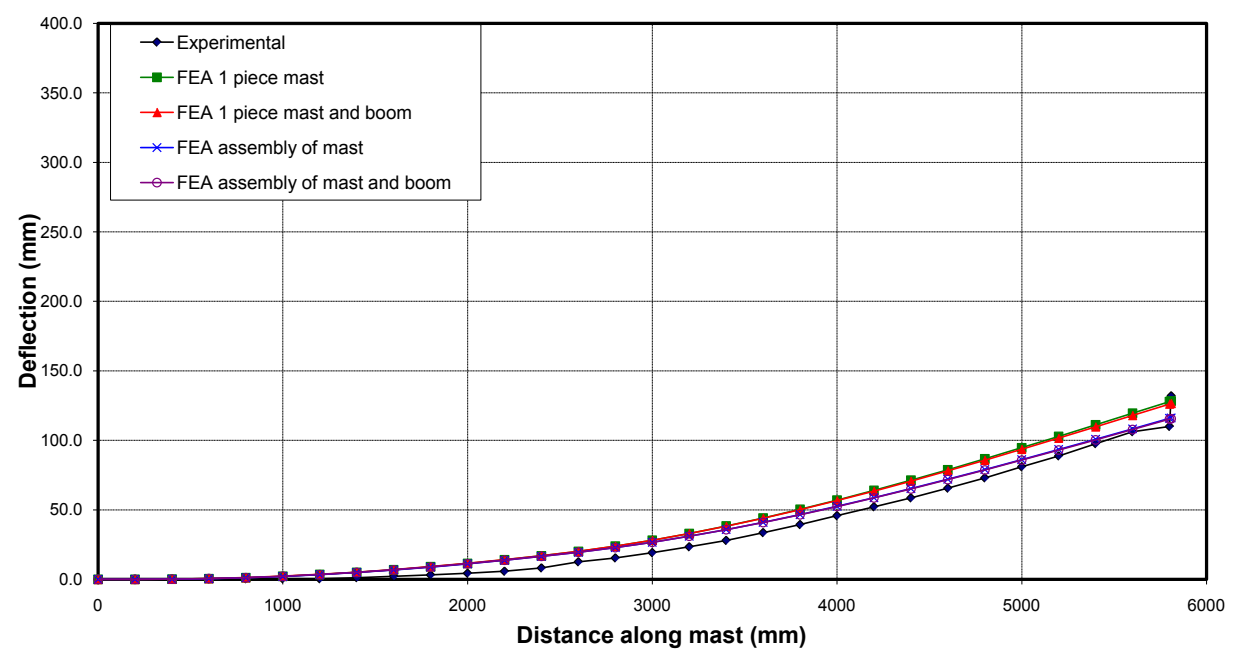

Figure 7: Comparison of experimental rig and various FEA models in light wind.

\section{Heavy Wind Conditions}

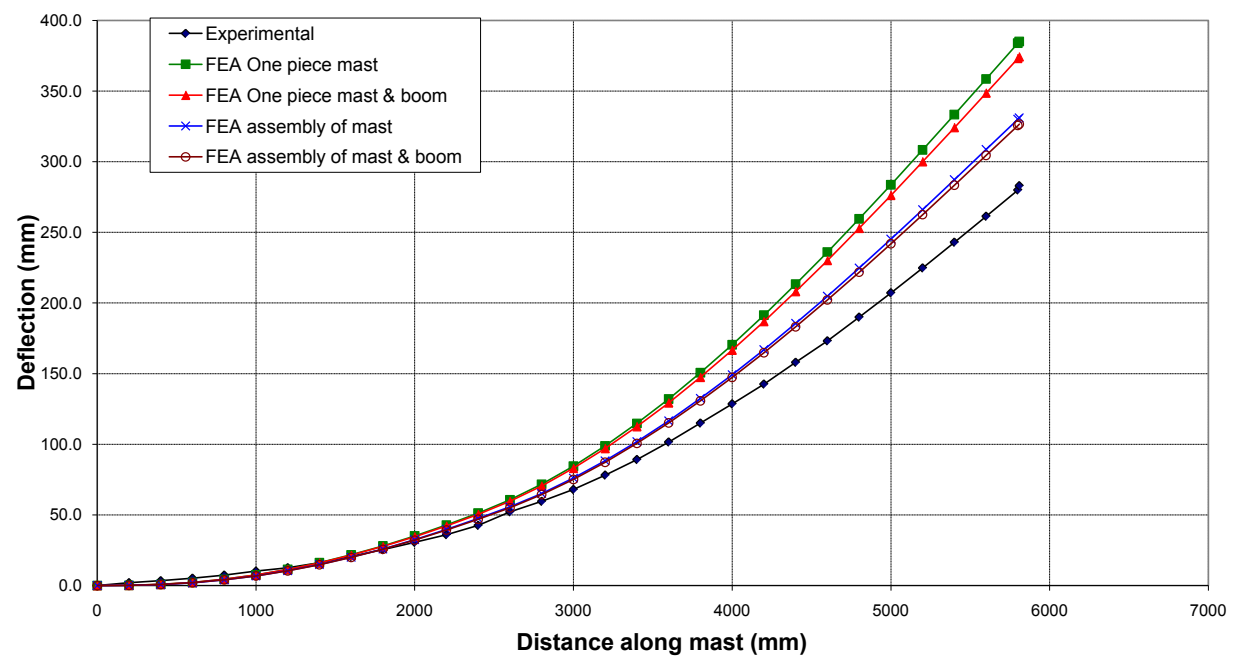

Figure 8: Comparison of experimental rig, and various FEA models in heavy wind. 


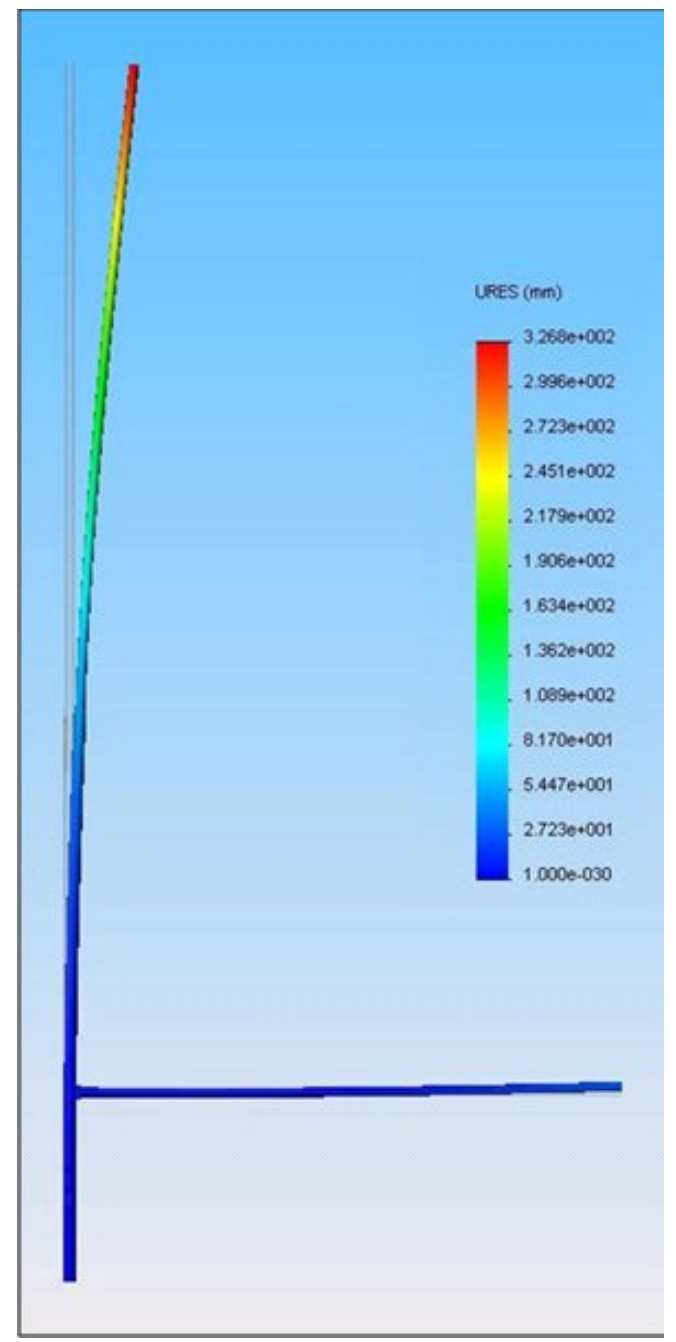

FigURE 9: FEA model of mast and boom assembly showing maximum deflection of the mast at the tip. 


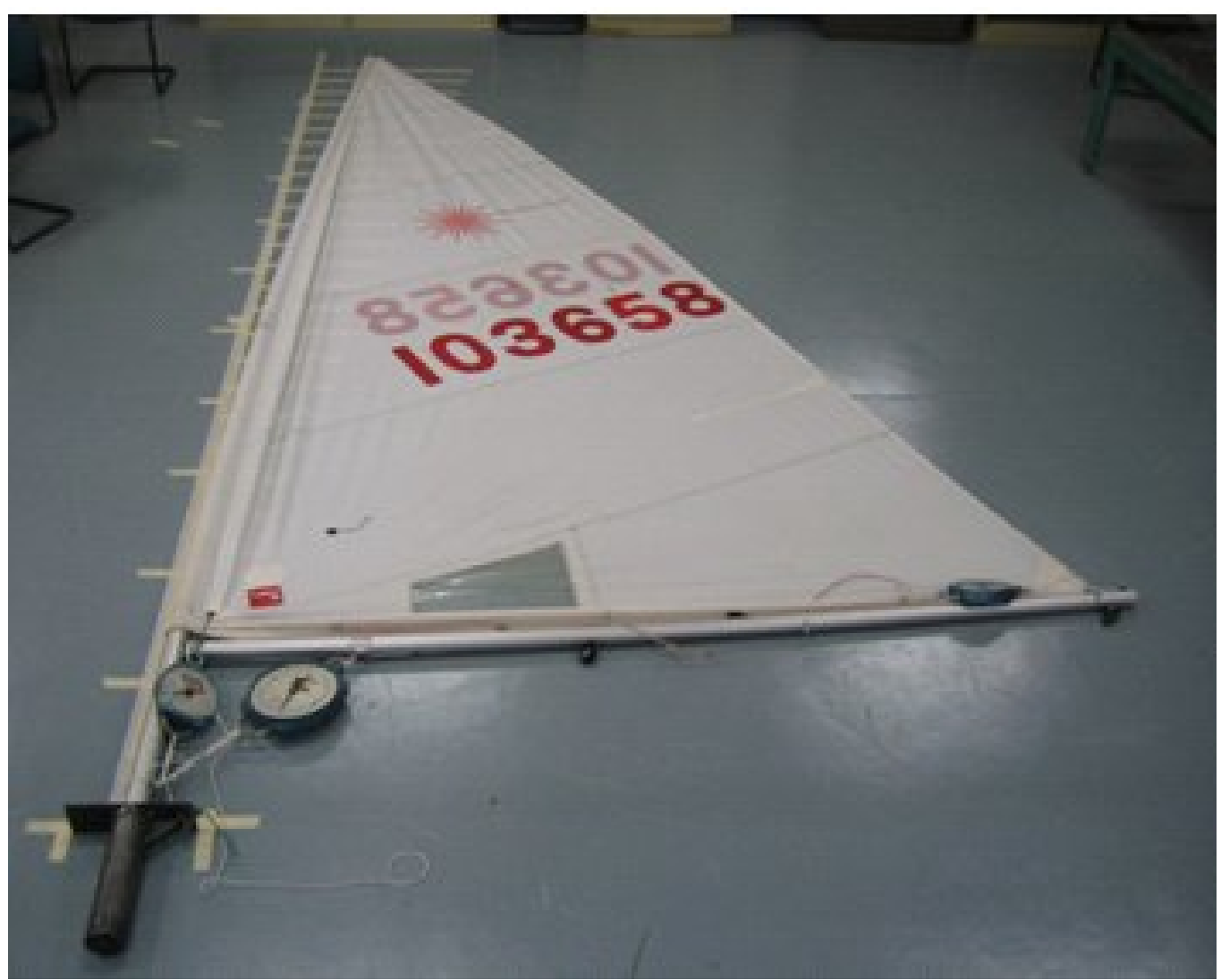

FiguRE 10: Experimental rig of mast and boom assembly showing maximum deflection of the mast at the tip. 
so gain an overall sailing advantage, enabling the Laser to achieve maximum (or optimum) speeds.

\section{Conclusion}

An investigation is undertaken to determine the deflection caused by trimming of the sail as well as the creation of a FEA model to predict this deflection. Initially, a basic FEA model has been created, reflecting a simple beam which can be analysed using an analytical approach. This basic model is then refined incrementally through the introduction of detail to ensure that an improvement in accuracy could be measured from previous iterations.

In order to validate the FEA model, an experimental testing regime is undertaken and trialled on a sail rig for different wind conditions (light, 0-3 knots; and heavy $17+$ knots), to establish the forces occurring within the sailing lines and the resultant deflections recorded for these different conditions. Validation has been achieved through the comparison of the experimental rig and the FEA models. From this the final iteration of the FEA model the FEA assembly of mast and boom model was selected as the model for predicting the deflection in a Laser yacht mast.

The FEA assembly of mast and boom model showed error in the results as would be expected in any model. In light wind conditions, due to the variability and small measured deflection in the experimental rig the FEA model is not capable of accurately predicting the deflection. Yet, for the higher wind conditions (heavy) the error is acceptable when predicting deflection due to trimming of the sail. Although emphasis is placed on statically applied forces and analysing their effect on deflection under different loading conditions, the results give an indication to a sailor as to the appropriate mast deflection under different wind conditions.

The FEA assembly of mast and boom model is the model which can be used for the prediction of deflection of a Laser yacht mast in wind conditions higher 
than 3 knots, and so improve the speed the Laser to achieve maximum speed.

Acknowledgements We thank Md. Samsuzzoha for his help in preparation of the manuscript.

\section{References}

[1] Anon, SolidWorks - COSMOSWORKS, Solidworks, Concord, MA, 2008, CAD FEA Software. C471

[2] P. Benham, R. Crawford, and C. Armstrong, Mechanics of Engineering, Pearson Education Ltd., England, 1996. C468, C469, C470

[3] D. Boote and M. Caponetto, Numerical Approach to the Design of Sailing Yacht Masts, The Tenth Chesapeake Sailing Yacht Symposium, ed Anon, Society of Naval Architects and Marine Engineers, Annapolis, 1991. C462

[4] H. Enlund, A. Pramila, and P. Johansson, Calculated and Measured Stress Resultants in the Mast And Rigging of a Baltic 39 Type Yacht, Transactions of the Royal Institution of Naval Architects Part B: International Journal of Small Craft Technology 148 (1984) 41-49. C462

[5] G. Grabe, The Rig of the Research Sailing Yacht DYNA Measurements of Forces and FEA, High Performance Yacht Design Conference 4-6, December, Auckland, 2002. C462, C464

[6] G. Grabe, The Rig of the UCA - Finite Element Analysis, International HISW Symposium Yacht Design and Construction, Amsderdam Nov 15-16 2004. C462 
[7] ISAF, IOC Confirms 10 Sailing Events For London 2012 Olympic Games, Centreboard Classes, International Sailing Federation, London, 2009. http://www. sailing.org/news/29214.php C462

[8] L. W. E. Media, Nautel Laser Masters World Championship, Margaret's Bay, 2009. http://can09. laserinternational.org/ C462

[9] D. D. Pearson, Tom Slingsby crowned 2008 Laser world champion, 2008. http://www.sailing.org/news/22202.php C462

[10] R. Shenoi, P. Conti, S. Turnock, and M. Scarponi, Mini 6.50 Mast Optimisation Using a Design of Experiment Approach and Finite Element Analysis Simulation, Transactions of the Royal Institution of Naval Architects Part B: International Journal of Small Craft Technology (B1) 148 (2006) 41-49. C462

[11] R. L. Tillman, The Complete Book of Laser Sailing, McGraw-Hill, International Marine/Ragged Mountain Press, Thomaston, 2000. C462, C463, C464

\section{Author addresses}

1. A. S. Blicblau, Faculty of Engineering and Industrial Sciences, Swinburne University of Technology, Hawthorn, Melbourne Australia. mailto:Ablicblau@swin.edu.au

2. M. Singh, Faculty of Engineering and Industrial Sciences, Swinburne University of Technology, Hawthorn, Melbourne Australia.

3. A. Thwaites, Faculty of Engineering and Industrial Sciences, Swinburne University of Technology, Hawthorn, Melbourne Australia. 
4. N. Welsh, Faculty of Engineering and Industrial Sciences, Swinburne University of Technology, Hawthorn, Melbourne Australia. 